\title{
Misteri Situs Wonoboyo
}

\author{
Ph. Subroto
}

Keywords: Hindu-Buddha, classical, settlement, characteristic, archaeology

\section{How to Cite:}

Subroto, P. Misteri Situs Wonoboyo. Berkala Arkeologi, 13(3), 1-11. https://doi.org/10.30883/jba.v13i3.612

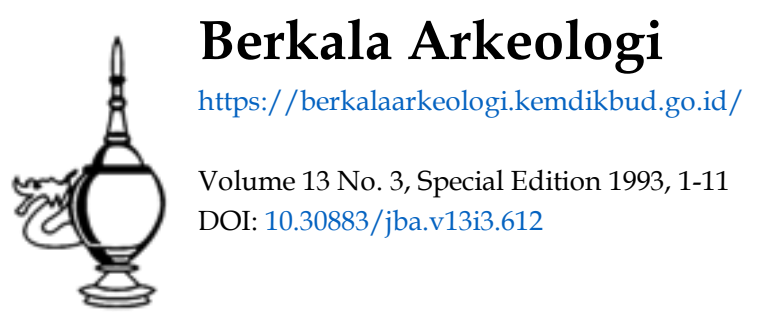

\section{(c) (i) (3) (2)}

This work is licensed under a Creative Commons Attribution-NonCommercial-ShareAlike 4.0 International License. 


\section{MISTERI SITUS WONOBOYO}

Olen:

Ph. Subroto

\section{RegIATAN ekskavasI}

\section{A. Ekskavasi I}

Sejak situs Wonoboyo ditemukan secara tidak sengaja pada tangsal 17 Oktober 1990, sampal sekarang sudah dilakukan beberapa kali kegiatan penggalian, dengan tujuan untuk menyelamatkan situs dari kerusakan, di samping tujuan yang berhubungan dengan keilmuan. Kegiatan pertama kali dilakukan oleh Suaka Peninggalan Sejarah Purbakala Propinsi Jawa Tengah pada tanggal 5-9 November 1990 bekerja sama dengan Jurusan Arkeologi Fakultas Sastra Universitas Gadjah Mada dan Balai Arkeologi Yogyakarta. Di Calam kegiaten ini telah dilakukan penggalian selama 5 hari, dengan iujuan pokok untuk mencari dan mengumpulkan data arkeologis yang dapat dipakai sebagal indikator bahwa Wonoboyo betul-betuil merupakan situs arkeologi. Upaya ini dilakukan mengingat temuan emas dan perak yang ditemukan sebelumnya oleh penduduk setempat, secara !lmiah dianggap belum cukup meyakinkan untuk digunakarl sebagai indikator. Di dalam penggalian tahap pertama ini telah ditemukan beberapa artefak yang berupa: fragmen gerabah (kereweng), fragmen keramik asing, dan fragmen bata kuno. Meskipun data artefak yang ditemukan dalam jumlah yang sangat sedikit, akan tetapi sudah dapat dianggap sebagai indikator bahwa Wonoboyo merupakan situs arkeologi.

\section{B . Ekskavasi II}

Untuk membuktikan bahwa Wonoboyo betul-betul merupakan situs arkeologi, maka pada tanggal 10-19 Desember 1990 dllakukan kegiatan ekskavasi untuk yang kedua kalinya, menyusul adanya berita tentang temuan struktur batu putih oleh penduduk setempat pada waktu menggali sumur untuk pengairan pekarangannya. Di samping struktur batu putih, oleh penduduk setempat juga telah ditemukan unsur-unsur bangunan berupa fragmen-fragmen bata kuno, fragmen 
batu putth, dan sebuah llngga patok terbuat darl batu putth. Ekskavasi yang kedua inl dilakukan oleh Suaka Penlnggalan Sejarah dan Peninggalan Purbakala Proplnsi Jawa Tengah bekerja sama dengan Jurusan Arkeologi Fakultas Sastra Universitas Gadjah Mada, dengan tujuan: menyelamatkan situs dari kerusakan leb/h lanjut, di samplng Juga untuk mengumpulkan data arkeologl yang dapat digunakan untuk kepentingan zoning dan kepentingan IImu. Di dalam penggallan ini telah ditemukan beberapa data berupa: tatanan batu kall, runtuhan batu putin, runtuhan bata kuno, struktur batu putih, dan hamparan batubatu gundulbatu kall. Jenis-jenis temuan tersebut ditemukan pada kotak-kotak galian di sekitar lingga patok dan struktur batu puth. Di samping itu, pada kotak-kotak galian yang lain, terutama di sektor barat, juga telah dapat dikumpulkan beberapa jenis temuan yang berupa: pecahan atau fragmen keramik asing, fragmen gerabah, dan hamparan batu-batu gundul.

Dengan adanya temuan-temuan tersebut telah memperjelas apa yang sebelumnya masih dipertanyakan sehubungan dengan situs Wonoboyo. Bahwa Wonoboyo sebagai situs arkeologi dapat dibuktikan oleh adanya iemuan-temuan baik yang bersitat struktural maupun non struktural. Namun demikian masih ada sebuan pertanyaan yang belum dapat dijawab sehubungan dengan iujuan penggalian ini, yaitu pertanyaan mengenal luas wilayah situs. Hal ini disebabkan oleh karena keterbatasan- keterbatasan yang ada, sehingga pemillhan kotak-kotak untuk keperluan zoning belum sepenuhnya terjangkau. Di samping itu Juga karena perkiraan mengenal luas situs ternyata tidak sesual dengan kenyataan, dalam arti bahwa situs Wonoboyo ternyata mempunyal ukuran leblh luas darl apa yang diperkl-rakan. Sebagal akibatnya, hasil kegiatan ekskavasi ini belum dapat dipakal untuk menentukan luas situsnya, karena kotak-kotak gallan yang telah berhasll digall belum menunjukkan batas-batas situs Wonoboyo.

\section{Ekskavasi III}

Keglatan ekskavasl berlkutnya yang merupakan keglatan yang ketlga kallnya dllakukan selama 10 harl dan berlangsung mulal tanggal 19 sampal dengan 28 September 1991. Ekskavasl inl merupakan keglatan bersama antara Bakosurtanal dengan Ditlinbinjarah, Jurusan Arkeologl Fakultas Sastra UGM. Suaka Penlnggalan Sejarah dan 
Peninggalan Purbakala Propinsl Jawa Tengah, Fakultas Geografl UGM, Balal Arkeologl Yogyakarta, dan Kanwil Depdlkbud Proplnsl Jawa Tengah. Adapun alasan dladakannya ekskavasl antara lain:

a. Setelah diadakannya ekskavasI tahap I dan II dapat diketahul bahwa Wonoboyo merupakan salah satu situs yang sangat potensial untuk kepentingan arkeologl dan ilmu pengetahuan.

b. Darl ekskavasi-ekskavasi sebelumnya, belum dapat ditentukan batas-batas situsnya, sehingga belum dapat digunakan untuk penetapan zoningnya.

c. Adanya kegiatan-kegiatan penduduk yang berlangsung di kawasan Situs yang dikhawatirkan dapat merusak keselamatan situs.

Dengan beberapa alasan seperti tersebut ol atas itulan maka kemudian ekskavasi untuk tahap III ini dilakukan, dengan aran iujuan:

a. Mencari kejelasan mengenal batas-batas viriayah situs. Kejelasan ini sangẫ diporlukan dalam kaitannya dengan rencana pengamanan situs.

b. Mengumpuikan data arkeologis yang dapat digunakan untuk keperiuan penelitian lebih lanjut, mengingat Jahwa sampai saat liu belum dapat ditentukan karakter atau tipe situsnya. Dengan memperoleh data yang dapat menunjukkan tipe situsnya, akan dapat digunakan sebagai arah pegangan untuk penelitian-penelitian selanjutnya.

Seperti halnya dengan penggalian-penggalian sebelumnya, penggalian yang ketiga inl telah menemukan data-data balk yang berupa artefak struktural, artefak non-struktural, data ekofak dan arang. Temuan-temuan tersebut yaitu: fragmen-tragmen gerabah, fragmen keramik asing, tatanan batu kall, hamparan batu kall, struktur batu putih, bata-bata kuno, arang, sisa kayu, dan tapak daun.

Dengan melakukan penggabungan data yang diperoleh darl tiga tahap penggallan inl, dapat dlperoleh gambaran mengenal beberapa aspek yang berhubungan dengan situs Wonoboyo. Dari temuan fragmen gerabahnya dapat diperoleh gambaran bahwa berdasarkan tebal 
tiplsnya fragmen, paling tldak ada tlga kelompok gerabah, taltu gerabah tipls $(0.20-0.50 \mathrm{~cm})$, gerabah sedang $(0.50-0.70 \mathrm{~cm})$, dan gerabah tebal $(0.70-2 \mathrm{~cm}$ ) (Penjelasan lebih lanjut. periksa: Laporan Kegiatan Penentuan Batas Wilayah Cagar Budaya dalam Rangka Penyelamatan Situs Wonoboyo, 1992). Yang menarik darl iemuan gerabah ini yaltu ditemukannya fragmen gerabah dengan jelaga yang cukup tebal menempel pada bagian luarnya. Temuan yang demiklan dapat menjadl petunjuk bahwa alat tersebut pernah digunakan secara intensis di atas perapian. Temuan lain yang menarlk yaitu berupa fragmen kepala kendi payung yang melihat bentuknya menunjukkan kesamaan dengan temuan sejenis di situs-situs percandian, misalnya candi Plaosan. Namun tidak berarti bahwa adanya temuan ini kemudian ditarik kesimpulan bahwa Wonoboyo merupakan situs percandian seperti halnya candi Plaosan.

Untuk temuan keramik asing, karena jumlahnya sangat sedikit dan sangat fragmentaris, maka sulit untuk direkonstruksi bentuknya, apalagi fungsinya. Namun demikian, dengan mengamałl warna dasar, glasir dan hiasannya, temuan keramik asing tersebut dapał digunakan untuk membantu di dalam perkiraan penangoalan secara relatif. Beberapa keramik yang ditemukan menunjukkan warna dasar putin kebiruan dengan glasir agak pekai. Jenis keramik semacam ini termasuk jenis keramik yang berasal dari Cina zaman dinasti Tang abad VII IX M.

Mengenai jenis temuan yang berhubungan dengan struktur bangunan dapat dibedakan antara temuan yang masih tersusun dan temuan yang sudah tidak tersusun. Bahan-bahan bangunan yang pernah digunakan antara lain batu putih, bata, dan batu kali. Namun karena datanya masih sangat sedikit, penggunaan masing-masing Jenis bahan tersebut belum dapat dipastlkan. Ada beberapa peiunjuk bahwa bahan batu putih digunakan untuk dinding pagar, iermasuk juga tugu batunya, sedang batu kalinya mungkin digunakan untuk dasar pagar. Untuk bahan batanya sebagian menunjukkan untuk dasar baglan semacam lantal dan mungkin juga untuk bagian bangunan lainnya.

Temuan lain yang cukup menarlk yaltu berupa arang, sisa kayu, dan tapak daun. Jenis-jenis temuan ini selain dapat digunakan untuk mengetahul keadaan lingkungan situs, juga dapat dimanfaatkan untuk penentuan penanggalan. Sampel arang juga sudah digunakan untuk keperluan penanggalan situs, dan darl analisis yang dllakukan oleh 
Batan, diperoleh hasil sekltar abad XV-XVIM. Karena sampel InI dlambll darl lapisan di ates culture layer, maka hasil penanggalan Inl berlaku untuk masa-masa sesudah situs Wonoboyo ditinggalkan. InI berant bahwa situs Wonoboyo dinuni sebelum abad XIV-XVI.

\section{Stratigrafi}

Data stratigrafl tanah pada kotak-kotak lubang penggalian menunjukkan adanya beberapa variasl dilihat dari ketebalan masingmasing strata dan sifat kandungan tanahnya, namun secara umum lapisan tanah pada situs Wonoboyo ini dapat dibedakan menjadi:

1. Lapisan tanah olahan (lapisan budaya masa kini)

2. Lapisan endapan lahar

3. Lapisan endapan pasir atau tuff kasar

4. Lapisan endapan lahar

5. Lapisan abu vulkanik atau lapisan tufi halus atau surface wash deposit ( endapan cucian pormukaan)

6. Lapisan tanah bucizya masa lampau.

Berdasarkan pengukuran ketebalan masing-masing stratanya dapat diketahul bahwa lapisan tanah budaya masa lampau berada pada kedalaman antara $200 \mathrm{~cm}$ sampal $220 \mathrm{~cm}$ dari permukaan tanah sekarang. Keberadaan lapisan tanah budaya masa lampau foaleo soil scape) sedalam ini karena tertimbun oleh endapan lahar dan endapan fluvial yang berasal dari erupsi gunung Merapi. Lapisan tanah ini mempunyai ciri-clrl: warna coklat gelap, teksiur pasir bergeluh, gembur, dan dalam keadaan basah agak lekat. Sebagal buktl Dahwa lapisan tanah ini merupakan paleo soil sca,o yaltu dengan ditemukannya data-data arkeologis baik yang berupa artefak, ekofak maupun feature. Temuan-temuan ini berada pada satu lapisan yang mempunyai ketebalan rata-rata $55 \mathrm{~cm}$. Di dasar lapisan ini, pada kotak-kotak tertentu ditemukan susunan atau tatanan batu putih, batu kall, atau bata, sedang dl atasnya sering dijumpai adanya reruntuhan bagian-baglan struktur yang terbuat darl bahan yang sama sepertl yang masih tersusun. Hal inl menunjukkan bahwa situs ini setelah tldak dlgunakan (ditinggalkan), karena sesuatu hal kemudian runtuh dan tertutup tanah. Reruntuhan yang telah tertutup tanah tersebut 
kemudian tertutup lagl oleh lapisan abu vulkanlk atau lapisan tuff halus yang tebalnya $15-20 \mathrm{~cm}$. Dengan kata laln, pada waktu abu vulkanik tersebut menutupi situs. Wonoboyo, sltus tersebut sudah dalam keadaan runtuh dan tidak dihuni lagi.

\section{Permasalahan}

Meskipun telah diakui bahwa sebagal sltus arkeologi, Wonoboyo memillki jenis-jenis temuan yang termasuk luar blasa atau bahkan fantastlk, akan tetapl hasll ekskavasi sampal taraf ini masih sangat sedikit untuk dapat mengungkap dengan tuntas misteri situs Wonoboyo.

Keterbatasan ini memunculkan berbagai permasalahan. Masalah yang pertama adalah tentang tipe situs. Walaupun tidak bisa dikatakan bahwa situs Wonoboyo adalah situs seremonial, akan tetapl belum blsa disimpulkan bahwa situs Ini adalah situs pemukiman. Masih diperlukan data pendukung untuk menyimpulkan hal itu, sepertl data yang berhubungan deagan jalan, sumur, sampah, dan juga bangunanbangunan lainnya.

Permasalahan yang kedua berhubungan dengan kelompok yang menggunakan situs tersebut. Dilihat dari jenis temuan yang ada, balk berupa emas, sisa bangunan maupun temuan lepas lainnya, dapat diperkiraican situs Wonoboyo berhubungan dengan golongan masyarakat bangsawan, mungkin sekali bangsawan kerajaan. Namun kepastian mengena! nal itu masih membutuhikan data pendukung yang lebih baryak lagi. Jika data yang ada cukup lengkap tldak mustahil akan dapat diketahui golongan masyarakat yang pernah tinggal di situs itu dan bahkan hubungannya dengan penguasa pada waktu itu.

Permasalahan yang ketlga berhubungan dengan faktor penyebab gltinggalkannya situs pemukiman tersebut. Darl data stratlgrafl dapat diketahul bahwa di atas lapisan budaya situs Wonoboyo terdapat lapisan tuH, berupa abu vulkanis. Akan tetapl di dalam lapisan budaya Itu sendirl terdapat lapisan (strata) yang memberlkan tanda-tanda bahwa sebelum teftutup oleh laplsan tuff situs litu sudah ditinggalkan, dan mungkin dalam keadaan runtuh. Dengan demlkian, faktor penyebab ditinggalkannya sltus ltu masih menjadi tanda tanya. Masih dlbutuhkan data yang leblh banyak untuk dapat memecahkan masalah Inl.

Permasalahan yang laln berkenaan dengan pertanyaan: adakah 
hubungan antara sltus Wonoboyo dengan sltus-situs seremonlal lain yang ada dl sekttar Prambanan. Pertanyaan Inl muncul karena tordapat potunjuk-potunjuk bahwa sttus Wonoboyo berasal dari masa yang dlperkirakan sama dengan slitus-situs seremonlal di daerah Prambanan. Apalagl, mellhat karakter temuan dl kedua wllayah tersebut terdapat slfat-slfat yang sama, yaltu Hindulstis. Oleh karena ltu, sangat mungkln ada hubungan antar kedua wllayah tersebut.

\section{HARAPAN DAN - SARAN}

Sejauh Inl, data arkeologis yang telah berhasll dikumpulkan, balk data struktural maupun non-struktural, lebih menunjukkan cirlcirl profan darlpada clrl-cirl sakral (seremonlal) yang berasal dari masa Klasik Awal Jawa Tengah. Tipe situs semacam ini belum pernah ditemukan di dalam sejarah masa Klaslk dl Jawa Tengah. Data struktural menunjukkan bahwa di situs iersebut pernah berdiri bangunan (mungkin darl bata) yang dlkelllingl oleh pagar batu putih. Mengingat sebaran batu-batunya sangat luas, maka dapat diperklrakan bahwa situs Wonoboyo merupakan suatu kompleks.

Adanya temuan emas dan perak yang ditemukan dalam jumlah yang sangat besar, dapat memberl arah pemlkiran terhadap stratlfikasl soslal masyarakat yang menghunl situs tersebut. Bahwa kawasan situs Wonoboyo pernah dihunl atau dlgunakan oleh golongan masyarakat yang berstratlfikasl sosial tinggl dapat ditunjukkan darl temuan emas dan perak tersebut. Untuk memperkuat dugaan tersebut dapat didukung oleh data struktural yang menunjukkan bahwa di situs Wonoboyo, pernah berdirl suatu kompleks bangunan yang dikelilingl oleh pagar batu putlh, sepertl telah disebutkan dl muka.

Data laln yang berupa fragmen keramlk, terutama keramlk asingnya, menunjukkan jenis-jenls keramlk yang tidak biasa dim|llk| oleh masyarakat kebanyakan, tetapl millk golongan yang mempunyal kedudukan tinggl. Dari data gerabahnya terdapat Indlkasl adanya bekas penggunaan yang Intensli, yaltu adanya jelaga yang cukup tebal. IndlkasI InI memborlkan gambaran terhadap penggunaan benda tersebut untuk keperluan sehari-harl (fungsl teknomlk) darl pada untuk keperluan upacara atau seremonlal (fungsl ldeoteknlk). Hal-hal tersebut dl ataslah yang mendasarl pemlkdran adanya kemungklnan 
bahwa sltus Wonoboyo merupakan sltus pemukiman atau sltus hunian, bukan situs seremonial. Namun untuk memastlkannya, masih diperlukan data yang lebih banyak lagl. Data inl akan diperoleh apanblla dilakukan ekskavası lanjutan, dengan sasaran:

1. Memastlkan apakah situs Wonoboyo merupakan situs pemukiman atau bukan. Untuk tujuan Inl perlu diupayakan adata antara lain berupa struktur bangunan yang menunjukkan sifat profan, beserta fasilitas bangunannya yang dapat menunjukkan perbedaan fungsi bangunan yang satu dengan bangunan yang lalnnya; bekas-bekas jalan, bekas-bekas parit, bekas sumur, dll.

2. Mencarl jawaban sehubungan dengan masyarakat atau golongan yang pernah menggunakan situs tersebut. Apakah situs tersebut berhubungan dengan kerajaan Mataram flindu yang pernah berkembang di Jawa Tengah antara abad Vis - X M ? Mengenal hal $\mid \mathrm{nl}$, dałå yang berupa tulisan (paieografi), keramik cina, can relief akan sangat diperlukan. Secara paleografis, tulisan-tullsan yang terdapai pada temuantemuan emas menunjukken kurun wakiu antara abad $\mathrm{X}$ - $X$ M. Demikian juga dengan jenls-jenis keramiknya, lerutama keramik asingnya, mayoritas menunjukzan ciri-ciri keramik dari dinasti Tang antara abad VII - IX M. Mengenai relieś yang terdapat pada salah sâu temuannya, yang menggambarkan cerlta Ramayana dapat digunakan sebagal bahan bandingan dengan relief cerita yang sama yang terdapat pada candi Prambanan. Yang perlu diperhatikan yaitu bahwa dengan adanya rellef cerlta tersebut, dapat diperkirakan bahwa masyarakat yang menggunakan alat tersebut adalah penganut agama Hindu. Bukti-bukti arkeologis dan historis menunjukkan bahwa pada masa Klasik Jawa Tengah di Jawa Tengah terdapat dua penguasa yang menganut agama Hindu dan yang menganut agama Buddha. Dengan demlkian dapat diperklrakan bahwa golongan masyarakat yang pernah mendlami situs Wonoboyo bukan penganut agama Buddha.

3. Mencari hubungan antara situs Wonoboyo dengan situs-situs seremonlal klasik yang banyak terdapat dl daerah Prambanan dan sekltarnya. Untuk tujuan inl, terlebih dahulu tujuan-tujuan nomor 1 dan 2 harus sudah dapat dipastlkan. InI berartl bahwa tlpe situs dan pendukungnya sudah harus dapat ditentukan, baru 
kemudlan dlhubungkan dengan situs-situs dl Prambanan yang relath sudah depat dlperkirakan perlode dan pendukungnya.

Apablla data yang diperiukan dapat dlperoleh dalam ekskavasi Inl, maka mlsterl sltus Wonoboyo pastl akan segera terungkap. Terungkapnya misteri Inl berantl akan membuka 3 kemungkinankemungkinan baru adalam bldang sejarah Indonesia Kuno. SepertI diketahul bahwa sampal saat Inl di Jawa Tengah belum pernah ditemukan situs yang menunjukkan bekas kraton darl masa Mataram Kuno. Hal Inl sangat Ironls, mengingat di Jawa Tengah terdapat banyak sekall peninggalan arkeologi berupa bangunan-bangunan candi darl perlode Mataram Kuno, balk candl-candl yang bersifat Hindu maupun Buddha. $\mathrm{Di}$ antara candl-candi tersebut terdapat candi-candi kerajaan yang dipakal untuk melakukan upacara-upacara kenegaraan. Kemungkinan bahwa Wonoboyo merupakan pusat keraJaan Mataram Kuno akan dapat dibuktikan dari ekskavasi-ekskavasi yang akan datang. Kalau di Jawa Timur dikenal Trowulan sebagal pusat kerajaan Majapahit abad XIII - XV M, maka ada harapan Wonoboyo sebagai pusat kerajan Mataram Kuno abad XIII-XV M. maka ada harapan Wonoboyo sebagal kerajaan Mataram Kuno abad VII-X M.

Mellhat kenyataan bahwa situs Wonoboyo merupakan situs arkeologl yang penting dan mempunyal prospek cerah, maka untuk menghindarkan hal-hal yang dapat merugikan kelestarian dan - keselamatan situs tersebut, kiranya perlu segera dilakukan tindak lanjut penanganan situs inl. Tindak lanjut inl dapat dilaksanakan melalul penelitian dan ekskavasl secara terencana dan berkesinambungan. Hanya denagn cara Inl data yang dikandung oleh situs Wonoboyo akan dapat terselamatkan, dan misterl situs inl akan dapat terungkap.

\section{KEPUSTAKAAN}

1. Laporan EkskavasI Wonoboyo I, II, III.

2. Bahan Sarasehan di Kabupaten Katen. 

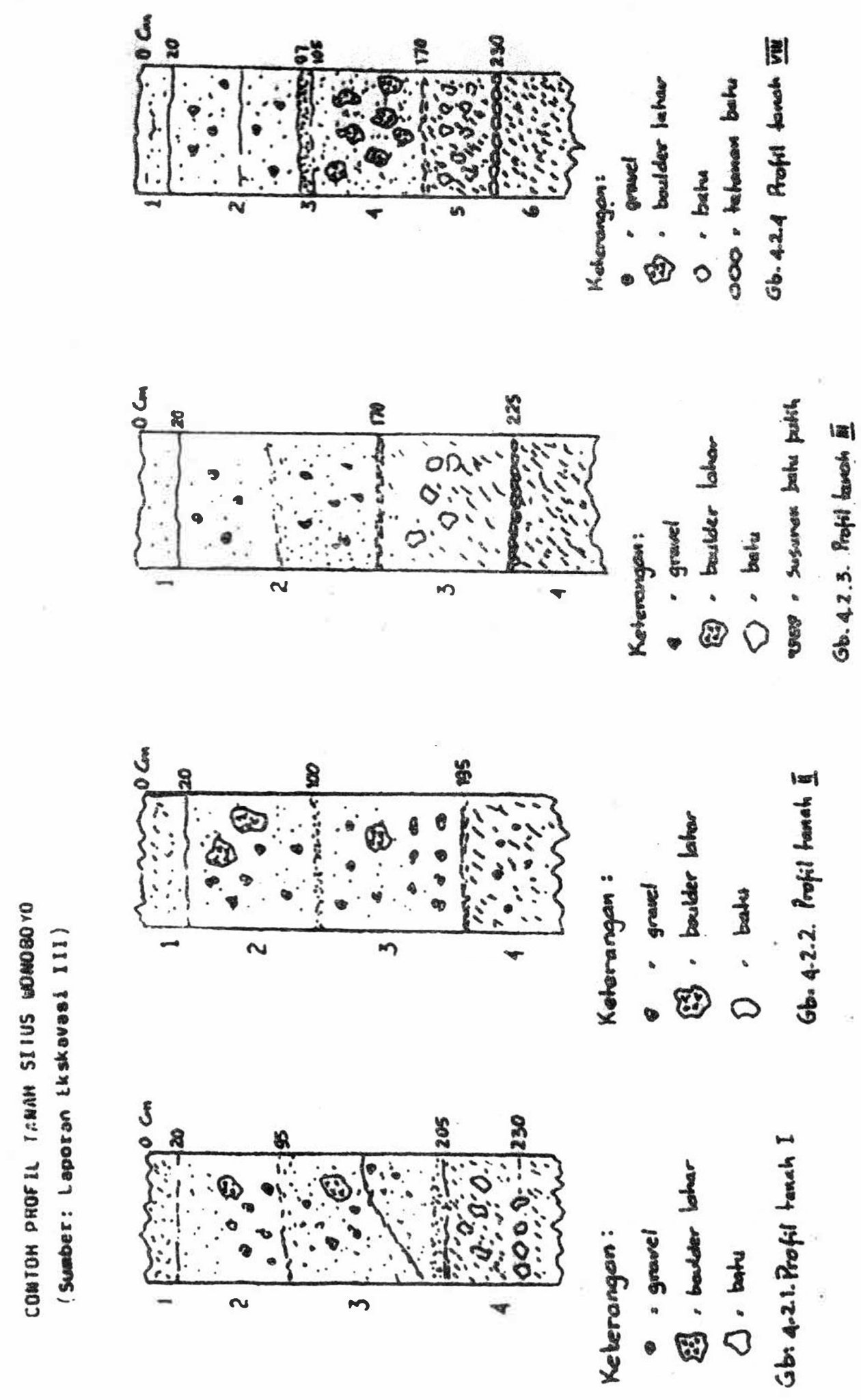


\section{PEDOSTRATIGRAFI SITUS WONOBOYO}

(Sumber: Laporan EkskavasI III)

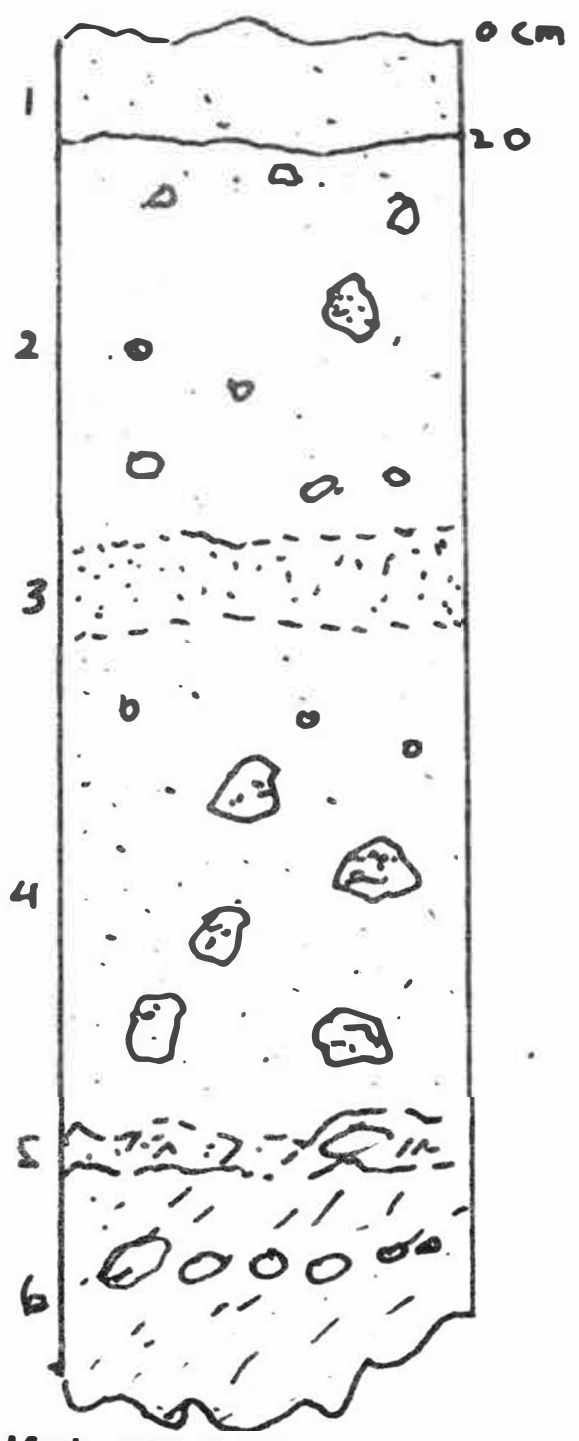

1 Laplsan olah, aktivitas budaya masa modern.

2. Endapan lahar

3. Endapan pasir atau tuff kasar.

4. Endapañ lahar.

5. Endapan tuff halus atau abu gunungapl atau endapan cucian permukaan (surface wash deposite)

6. Lapisan tanah budaya masa lampau

Keterangan:

$\boldsymbol{\theta}$ : gravel

$\mathcal{E}$ : boulder lahar

$\Xi$ : batu 